be provided at modest cost by permanent magnets or electromagnets. On the other hand, highresolution nuclear magnetic resonance spectroscopy demands a uniformity of one part in $10^{2}$ and stability to better than this. A large carefully engineered electromagnet with first-class electronic regulation will meet the requirements, and indeed such a magnet is marketed in the United States. A large carefully engineered permanent magnet with temperature stabilization is equally satisfactory. In either case the cost is high. Dr. Richards outlined Purcell's method of smoothing out irregularities of field caused by inhomogeneity of the magnet alloy; the pole caps are made of layers of soft iron and diamagnetic material which attenuate the irregularities in much the same manner that electrical fluctuations are reduced by the successive sections of a filter. In the discussion which followed, diverse views were expressed on most aspects of design-pole-cap contour and figuring, shims, pole-cap material, magnetic material, yoke configuration. It seems that much has yet to be learnt before one can confidently assert what are the best and most economical designs of magnets suitable for high-resolution work.

At a business session held during the symposium, a proposal was approved to form a Radiofrequency Spectroscopy Group which would arrange future occasional meetings. For this purpose radiofrequency spectroscopy was deemed to cover work at all frequencies up to about $10^{11} \mathrm{c} . / \mathrm{s}$., and therefore includes electron- and nuclear-resonances and also microwave spectroscopy of gases.

E. R. ANDREW

\section{ANNUAL CONFERENCE OF THE PHILOSOPHY OF SCIENCE GROUP}

$\mathrm{T}$ HE first annual conference of the Philosophy of Science Group of the British Society for the History of Science was held during September 21-23 at Ashburne Hall, University of Manchester, under the chairmanship of Dr. G. J. Whitrow, chairman of the Group, and was attended by about fifty members and guests. Mr. R. F. J. Withers acted as conference secretary.

Symposia were held on "Cybernetic Models and Thought Processes", "The Nature and Scope of Scientific Method", "The Status of Irreversible Processes in Physical Theory" and "The Role of Historical Explanations in Science".

In the first symposium, papers were read by $\mathrm{Dr}$. W. Mays and Dr. W. Ross Ashby, and Prof. J. H. Woodger took the chair. Dr. Mays raised the question of the adequacy of cybernetic models for human thinking and learning behaviour. $\mathrm{He}_{e}$ held that the question, 'Can machines think ?' is not simply a semantic but a factual one; and the answer is 'Yes' only if machines and humans reach their conclusions by similar processes. Dr. Ashby was interested in giving a clear account of 'model' as something that is from a relevant point of view similar to that which is modelled, so as to lead to results which can be tested. To be tractable, however, a model must also be an over-simplification. Hence, all models of the brain have been inadequate, but they have thrown light on aspects of it; in particular they have focused attention on the basic question, 'How much in. formation is involved in this process ?' Subsequent discussion centred around the concept of model, its nature and role. There seemed to be a general consensus of opinion that, although mental processes have not so far been adequately represented by cybernetic models, some models have proved useful.

A connecting link developed between this discussion and the next one, for in discussing models attention was directed to the role of theories in science. This question figured prominently in the second symposium. For this the chair was taken by Dr. J. O. Wisdom, and the opening paper was given by Dr. G. W. Scott Blair on "Scientific Method as a Specialized Intellectual Activity". He considered that the mental processes involved in scientific activity consist of observing, selecting, relating and deducing. He pointed out that there are parallel processes involved in tests of general intelligence, and therefore claimed that the specialized mental activity that goes to make science is not unique but is shared by other intellectual activities. Prof. R. O. Kapp followed with a paper on "What is a Law in Physics?" He laid great stress on what he called the principle of minimum assumption. He showed with examples that this is not merely a method of economy but also provides a means of deriving important results in theoretical science. He considered, for example, that Dirac could not have predicted the positron without (though perhaps not overtly) relying on this principle. Mr. Z. M. T. Tarkowski then spoke on "The Interaction of Experiment and Theory in Science". After giving an account of the general way in which theories are used, he contended that Galileo's experimental results did not bear out his kinematical hypotheses, and inferred that a theory may have the right to be regarded as possibly true even though the evidence is against it.

The third symposium was more specialized. The chairman of the Group took the chair, and Prof. M. S. Bartlett read a paper on "Irreversibility and Statistical Theory", in which he presented a survey of the development up to the present day of the concepts of irreversibility and entropy. He pointed out that the paradoxes of reversibility reappear in statistical mechanics. He suggested that statistical reversibility for very small systems is consistent with their possible lack of any intrinsic time-direction. Mr. L. L. Whyte then spoke on "The Mathematics of One-way Processes", the traditional problem being to account for one-way processes moving towards equilibrium on the assumption that elementary atomic processes are reversible. This he regarded as over-simplified, since owing to the effect of magnetic fields no single electronic process is reversible unless all electronic motions are simultaneously reversed. A more fertile problem may be to determine conditions under which certain constant parameters can provide satisfactory approximations in a theory of one-way processes. In the discussion which followed, a short note was presented by the chairman from Prof. K. R. Popper, who argued that no logically satisfactory version of the second law of thermodynamics exists. He suggested a possible reformulation of the law, but directed attention to the serious logical difficulties in the way of any reformulation.

In the final symposium, Mr. R. P. Gould discussed "The Place of Historical Propositions in Biology". He contrasted explanation in science with explanation in history. After describing similarities and differences between the kinds of statement found in science 
and history, he aimed at showing how scientific explanatory hypotheses can be used to explain what has happened in the past. In this way it is possible to give scientific explanations about the evolution of extinct organisms; but he considered that, because of inadequate information, statements about the physiology, biochemistry, and so on of extinct organisms must be treated with caution. Mr. J. W. N. Watkins then spoke on "Historical Explanations in the Social Sciences". He advocated "methodological individualism' as an essential principle for social science. According to this principle, there are no 'holistic' sociological laws that are irreducible to laws about the situations, dispositions, aims, etc., of individual persons. $\mathrm{He}$ claimed that the principle could account for organic-like social behaviour, and he described ways in which explanations of social regularities and of unique historical events could be framed in accordance with it. Mr. R. F. J. Withers, who took the chair, pointed out that there is a difference between scientific explanation and the use of techniques; and the general discussion showed that several biologists were loath to look on scientific explanation, when applied to evolution, as historical.

Animated discussions took place in each symposium. The conference was generally felt to have justified the efforts of those responsible for organizing it, particularly as it became evident that greater clarity concerning problems of scientific method and ex. planation could facilitate further progress in science itself. Plans for future conferences outside London were discussed. It was provisionally arranged that the next will be held at a week-end towards the end of September 1957. An announcement will be made in The British Journal for the Philosophy of Science early in 1957.

\section{NUFFIELD FOUNDATION REPORT FOR 1955-56}

$\mathrm{T}$ HE eleventh report of the Nuffield Foundation, covering $1955-56^{*}$, specially emphasizes in its introduction the general ideas on which the Foundation attempts to plan its operations. Concerned to finance projects that may yield dividends not in terms of cash but of public good, the Foundation inquires first into the credit-worthiness of the applicant; second, into the originality of his idea ; and third, into the soundness of his project. It is least interested in investments which will produce a modest return, and with depressing frequency it may find that the number of good projects exceeds the number of good men to execute them. Moreaver, the Foundation must also go out and seek profitable investment. It is not its job to sustain work which everybody agrees ought to be done; it dare not even continue to support indefinitely its own successful schemes, lest it quickly consume resources out of which new ones can be attempted. In this seeking of new and rewarding ventures, the Foundation is greatly helped by its visitors and advisers, including those from the universities, learned societies, research institutes, philanthropic societies, hospitals and government departments, who bring ideas as well as information. The Foundation must be free to make rapid changes of emphasis in its interests, and it is

* The Nuffield Foundation. Report for the Year ended 31 March, 1956. (Eleventh Report.) Pp. 160. (London: Nuffeld Foundation, 1956.) important that the size of a grant should be nicely judged so as not to stunt nor stifle. Its funds, too, should not be scattered over a wide range of unrelated. schemes, and its policy should be neither vague nor rigid, its programme neither shapeless nor fixed.

Grants for biological research in the United Kingdom include a further grant of $£ 2,410$ for one year to 'The Queen's University of Belfast for studies on population genetics in Northern Ireland under Prof. A. C. Stevenson which are gradually building up a detailed knowledge of the frequency and distribution of specific genes. A grant of $\mathfrak{1 4 , 8 0 0}$ over five years has been offered to the Plant Breeding Institute, Cambridge, for the salary of a plant cytologist with some knowledge of biochemistry to work mainly at the Institute under the joint supervision of its director, Dr. G. D. H. Bell, and of Prof. J. S. Mitchell, of the Department of Radiotherapeutics, on the modification by chemical means of radiation effects in plants such as broad beans and barley. A further grant of $£ 4,500$ over 1956-59 has been made to the University of Glasgow for the work under Prof. G. Pontecorvo on the genetics of micro-organisms, which it is hoped may lead to the discovery of a chemical basis for the genetical phenomena of 'crossing over'. A further grant of $\mathfrak{f} 14,200$, payable in declining amounts over five years to the Royal Anthropological Institute, London, is to enable the Nuffield Blood-Group Centre to continue its work until other financial provision can be made, and the grant to the Lister. Institute of Preventive Medicine, London, for the work on the chemical analysis of immunity-provoking agents has been renewed at the rate of $£ 3,000$ a year for a further five years.

A grant of $£ 4,850$ over three years has been made to the University of Oxford in support of Dr. A. E. M. Weddell's study of free nerve terminals in the cornea of untreated leprotic patients, and an additional grant of $£ 12,000$ over three years has been made to University College, London, for work on the problems of analogues for the cerebral mechanisms involved in the learning processes of the octopus ; $£ 6,300$ over three years to the Institute of Psychiatry, University of London, is for Prof. H. Mcllwain's work on the control of metabolism in normal mammalian cerebral tissues. Another grant to University College, London, of $£ 4,246$ over three years, is for the construction of a micromanipulator which will transmit the sense of touch. The Foundation has provided $£ 2,500$ for the Department of Agricultural Botany, University College of Wales, Aberystwyth, for equipment to control light, temperature and humidity in research on the influence of environment on the mechanics of growth and inheritance. A final grant of $£ 2,700$ over three years has been made to the University of Cambridge for Dr. J. W. Millen's and Dr. D. H. M. Woollam's work on hydrocephalus in rabbits due to deficiency of vitamin $A$, and a grant of $£ 2,530$ has been offered for work on the flight muscles of the bumble bee and on the electric discharges from fishes. The Foundation has also offered $£ 1,500$ a year for a further two years to the University of Durham in support of Prof. J. Baddiley's work on the structure and synthesis of co-enzyme $A$.

Other scientific grants include $£ 1,750$ a year for two years for the establishment of a lectureship in polar studies at the University of Durham; $\$ 8,000$ over four years to the Imperial College of Science and Technology, London, for Prof. R. M. Barrer's work on the synthesis and properties of natural and synthetic minerals, especially aluminosilicates ; $\$ 600$ for special 